\title{
Avaliação de Diferentes Suplementos para Vacas Mestiças em Lactação Alimentadas com Cana-de-Açúcar: Desempenho e Digestibilidade
}

\section{Márcio da Silva Vilela ${ }^{2}$, Marcelo de Andrade Ferreira ${ }^{3,4}$, Antonia Sherlânea Chaves Véras ${ }^{3}$, Mércia Virginia Ferreira dos Santos ${ }^{3}$, Iderval Farias ${ }^{5}$, Airon Aparecido Silva de Melo ${ }^{6}$, Ricardo Pimentel Ramalho6, Paulo Renato Barros Araújo ${ }^{7}$}

\begin{abstract}
RESUMO - O objetivo deste estudo foi avaliar o consumo, produção e composição do leite, digestibilidade dos nutrientes e eficiência alimentar de vacas mestiças de baixo potencial de produção, alimentadas com dietas à base de cana-de-açúcar. Foram utilizadas oito vacas mestiças ]! Holandês/Gir com peso vivo médio de $425 \mathrm{~kg}$, após o terço inicial de lactação. Os animais foram distribuídos em dois quadrados latinos (4x4), de acordo com a ordem de lactação e alimentadas com dietas completas à base de cana-de-açúcar, sendo, cana mais uréia (CAU); cana, uréia e farelo de algodão (CFA); cana, uréia e milho (CMM); cana, uréia e farelo de trigo (CFT). Os consumos de matéria seca (MS), fibra em detergente ácido (FDA), fibra em detergente neutro (FDN) e matéria orgânica (MO) foram superiores para as dietas com farelo de algodão e trigo. O consumo PB foi maior para o CFA em relação ao CAU. Os consumos de carboidratos totais (CHT), carboidratos não-fibrosos (CNF) e NDT apresentaram o mesmo comportamento, sendo superior para CFT e CFA em relação ao CAU. Os coeficientes de digestibilidade da MS e MO foram maiores para a suplementação com milho, porém a digestibilidade da $\mathrm{PB}$ foi superior para o CFA, em relação aos demais. Os coeficientes de digestibilidade da FDN e CHT foram maiores para o CMM em relação ao CFA. Porém, o coeficiente de digestibilidade da FDA foi inferior para o CFA. O teor de NDT foi superior para CMM e CAU em relação aos outros tratamentos, variando de 88,25 a 74,44\%. A produção de leite com correção para 4,0\% de gordura foi inferior para CAU comparada aos demais tratamentos. Não houve alteração nos teores de proteína e gordura do leite. No entanto, o CAU proporcionou as menores produções de proteína e gordura do leite. O CFA apresentou a menor eficiência alimentar.
\end{abstract}

Palavras-chave: consumo, produção e composição do leite, suplementação.

\section{Evaluation of Different Supplements for Lactating Crossbred Cows Fed Sugarcane: Performance and Digestibility}

\footnotetext{
ABSTRACT - The objective of this study was evaluate the intake, milk production and composition, nutrients digestibility and feed efficiency of crossbred cows of low potential of production fed diets based on sugar cane. It was used eight cows crossbred Holstein/ Gir, with medium live weight of $425 \mathrm{~kg}$, after the initial third of lactation. They were distributed in two Latin squares (4x4), in agreement with the lactation order, feeding with complete diets to the sugarcane base, being, cane more urea (CAU); cane, urea and cottonseed meal (CFA); cane, urea and corn (CMM); cane, urea and wheat meal (CFT). The intakes of DM, ADF, NDF and OM were higher for CFA and CFT in relation to the others. The intake CP was higher to CFA in relation to CAU. However, the intakes of THC, FNC and TDN presented the same behavior, being higher for CFT and CFA in relation to CAU. The digestibility for DM and OM were higher to CMM in relation the others; however the digestibility of the CP was higher to CFA, in relation to the others. Those digestibilities of the NDF, THC were higher to CMM in relation to CFA. However the digestibility of the ADF was lower to CFA in relationship the others. The levels of TDN were higher to CMM and CAU in relation the others, ranged from 88.25 to $74.44 \%$. The milk production corrected for $4.0 \%$ of fat was lower to CAU in relation to the others treatments. There was no alteration in the protein and milk fat levels. However, for protein and fat productions the milk, the treatment CAU was lower to the others. CFA presented to lower feed efficiency.

Key Words: intake, milk production and composition, supplementation

\section{Introdução}

A produção de leite é largamente dependente do consumo de energia e proteína metabolizáveis os quais, são altamente influenciados, tanto pela qualidade

da forragem e interação da forragem com a população microbiana do rúmen, quanto pelos fatores relacionados aos animais e a outros nutrientes da dieta (Allen, 1996).

Segundo Warnaars (1974) e Preston (1984), a

1 Parte da Dissertação do primeiro autor.

${ }_{2}$ Mestre em Zootecnia. R. 34, n. 193, CEP: 38302-006, Ituiutaba, MG. E.mail: vilelamarcio@yahoo.com.br

3 Professor do DZO - UFRPE - CEP: 52171-030 Recife, PE. E.mail: ferreira@ufrpe.br

4 Bolsista do CNPq.

5 Pesquisador do IPA.

6 Aluno do Doutorado do PDIZ - UFRPE.

7 Aluno do Mestrado do PPGZ - UFRPE.
} 
utilização da cana-de-açúcar como forrageira para bovinos apresenta algumas vantagens sobre outros volumosos, destacando-se: a) grande produção de massa por unidade de área; b) possibilidade de colheita em diversas épocas, podendo inclusive ficar no campo de um ano para outro, sem grande perda do valor nutritivo (auto-armazenamento); c) produção de rebrota, por ser uma planta perene, minimizando com isso os custos de produção; d) boa palatabilidade; e) digestibilidade e composição química, em termos de proteína e energia, não são reduzidas consideravelmente com o avanço da idade da planta; e f) riqueza em carboidratos solúveis, veículo excelente para a utilização de nitrogênio-não-protéico (NNP).

Por outro lado, a cana apresenta algumas limitações que devem ser consideradas. Conforme Preston (1982), seus carboidratos consistem em açúcares altamente solúveis, com alta taxa de degradação ruminal; possui elementos pouco solúveis (componentes da parede celular), com baixa taxa de degradação pelos microrganismos do rúmen; não contém amido; e seu nível de proteína é extremamente baixo. Preston \& Leng (1986) indicaram que deve haver suplementação com alimentos ricos em proteína sobrepassante, o que também foi relatado por Fernandes et al. (2001), e amido de baixa degradabilidade ruminal.

Baseando-se no potencial de fornecimento de proteína e amido sobrepassantes, Preston \& Leng (1984) classificaram alguns alimentos concentrados a partir de uma escala de 0 a 5 , tendo atribuído 1 e 5 para o grão de milho; 5 e 4 para o farelo de algodão; e 3 e 3 para o farelo de trigo, respectivamente, para proteína e compostos glicogênicos.

Alvarez Flores (1980) citou que a associação da cana-de-açúcar com compostos nitrogenados não protéicos (NNP) é possível, em razão do alto conteúdo de carboidratos facilmente fermentáveis dessa forrageira, tornando-a um substrato recomendado para ser usado com esses compostos, sem maiores riscos de intoxicação.

As forragens tropicais apresentam baixa digestibilidade e teor reduzido de proteína e, mesmo na estação de crescimento, não fornecem nutrientes suficientes para altas produções de leite e elevadas taxas de ganho de peso. Neste sentido, a suplementação é uma alternativa eficiente para a melhoria da produção animal, devendo o tipo de suplementação considerar a época do ano, nível de produção, custos e alimentos disponíveis. A vantagem, ou não, de suplementar dependerá da produção extra de leite ou carne obtida, causada pelo efeito do suplemento e, naturalmente, do custo deste último. Quanto maior for à resposta produtiva à suplementação, e quanto menor o custo do suplemento, mais propícias serão as condições econômicas da suplementação (Assis, 1986).

Biondi et al. (1978) e Fernandes et al. (2001) relataram que a cana-de-açúcar pode ser fornecida como único volumoso, desde que suplementada adequadamente com misturas de concentrado, não alterando a produtividade animal. Segundo Ravelo et al. (1978), a baixa degradação da cana no rúmen implica em limitação da taxa de reciclagem ruminal e, conseqüentemente, em baixo consumo. No mesmo sentido, Ærskov \& Hovell (1978) mostraram que a taxa de digestão da fibra da cana-de-açúcar é muito baixa no rúmen e que o acúmulo de fibra não digerível limita o consumo voluntário.

Nauffel et al.(1969) conduziram experimentos comparativos entre cana e silagens de milho e sorgo, e concluíram que as silagens foram igualmente eficientes para a produção de leite, enquanto a cana resultou em queda de produção e acentuada perda de peso dos animais.

Nogueira Filho et al. (1977) atribuíram o efeito depressivo da cana na produção de leite, ao elevado teor de sacarose, que promove distúrbios metabólicos ruminais, com depressão da digestão da celulose, quando o animal ingere grandes quantidades de alimentos ricos em açúcares facilmente digeríveis, pois esses carboidratos além de serem rapidamente fermentados, propiciam o desenvolvimento de espécies bacterianas próprias, em detrimento daquelas que digerem a celulose. Estes mesmos autores concluíram que a cana-de-açúcar não deve ser fornecida para o gado leiteiro como volumoso exclusivo, por não apresentar resultados satisfatórios. Observaram que vacas alimentadas com essa forrageira reduziram a produção de leite em 41,9\%, a cada quatro semanas, apresentando, inclusive, drástica perda de peso, de aproximadamente, $1 \mathrm{~kg} / \mathrm{vaca} / \mathrm{dia}$.

Biondi et al. (1978) avaliaram a substituição parcial e total da silagem de milho por cana-de-açúcar $(0,25$, 50,75 e $100 \%$ ) da matéria seca (MS) do volumoso, com aumentos da quantidade de concentrado, à medida que se elevaram os níveis de substituição, e encontraram redução linear na produção de leite com a inclusão da cana na ração. Entretanto, concluíram que, se corretamente suplementada, a cana-de-açúcar poderia substituir até $50 \%$ da silagem de milho. Nesse mesmo sentido, Ribeiro et al. (2000), trabalhando com 
as mesmas proporções de substituição da silagem de milho por cana/uréia, encontraram que a cana como volumoso exclusivo, ou em proporção superior a $50 \%$ limita o consumo alimentar, prejudicando o desempenho animal; o que também foi observado por Pires et al. (1999), que concluíram que, em dietas contendo altos níveis de concentrado, a silagem de milho pode ser substituída por cana-de-açúcar até níveis de $50 \%$ do volumoso, sem efeitos negativos na utilização de nutrientes, por vacas leiteiras de baixa produção.

Fernandes et al. (2001) utilizaram o Cornell Net Carbohydrate and Protein System (CNCPS) para simular o desempenho de vacas mestiças de baixa produção, alimentadas com rações contendo cana-deaçúcar, e estimaram produção média de $7,5 \mathrm{~kg}$ de leite/ dia, quando a dieta foi composta apenas por cana mais uréia e sulfato de amônia, e de $10 \mathrm{~kg} /$ dia para dietas, quando a cana foi suplementada com silagem e concentrado. Os referidos autores concluíram que os teores de fibra em detergente neutro (FDN) e lignina, exercem grande influência sobre a quantidade necessária de concentrado a ser incluída na dieta.

Coelho da Silva \& Leão (1979) relataram que a digestibilidade dos nutrientes depende das características do alimento, e não do animal. Por outro lado, Para McDonald et al. (1993), existem vários fatores que influenciam a digestibilidade, tais como composição dos alimentos e da ração, preparo dos alimentos, fatores dependentes dos animais e do nível nutricional, entre outros. Segundo o NRC (2001), em relação à composição, a digestibilidade e o consumo de MS são afetados pela fração de FDN, que, devido às baixas taxas de digestão, é considerada o componente dietético primário associado com o efeito de enchimento.

O objetivo deste trabalho foi avaliar o efeito de diferentes suplementos, considerando a classificação de Preston \& Leng (1984), para cana-de-açúcar sobre consumo e digestibilidade dos nutrientes, produção e composição do leite e eficiência alimentar de vacas mestiças 5/8 Holando/Zebu de baixa produção.

\section{Material e Métodos}

A pesquisa foi realizada na Estação Experimental da Empresa Pernambucana de Pesquisa Agropecuária (IPA), localizada na cidade de Itambé - PE, na Zona da Mata Norte, com precipitação pluviométrica média de $1.231 \mathrm{~mm} /$ ano e solo e textura franco - argilosa (terra preta), com $\mathrm{pH} 4,5$, e temperatura média anual de $28,3^{\circ} \mathrm{C}$, no período de janeiro a abril de 2001 .

Foram utilizadas oito vacas mestiças 5/8 Holando/ Zebu, com peso vivo (PV) médio de $425 \mathrm{~kg}$; período de lactação, em média, de 45 dias; e produção média de leite diária de $8,5 \mathrm{~kg}$, caracterizando animais de baixa produção; sendo quatro primíparas e quatro pluríparas.

Após combate de ectoparasitas, os animais foram estabulados em galpão de alvenaria coberto com telhas de cerâmica, com piso de alvenaria (com cama), e cochos individuais, para controle de consumo da dieta. Foi permitida a saída dos animais do estábulo duas vezes ao dia, com duração de quatros horas, para consumo de água e exercício.

As dietas foram formuladas de acordo com as recomendações do NRC (1989), para atender às exigências de vacas em lactação, com produção de leite de $10 \mathrm{~kg} / \mathrm{dia}$ com 4,0\% de gordura. Como volumoso foi utilizada a cana-de-açúcar, variedade SP 78-4764, proveniente da Estação Experimental de Itambé, cortada a cada dois dias e armazenada próximo ao estábulo, sendo despalhada no campo, picada juntamente com as pontas em máquina forrageira no momento de cada refeição. Os tratamentos consistiram de diferentes suplementos para a cana-de-açúcar (cana-de-açúcar e uréia (CAU); cana-de-açúcar, uréia e farelo de algodão (CFA); cana-de-açúcar, uréia e milho grão moído (CMM); e cana-de-açúcar, uréia e farelo de trigo (CFT), conforme Tabela 1.

Tabela 1 - Composição percentual das dietas experimentais com base na matéria seca

Table 1 - Percentage composition of the experimental diets on dry matter basis

\begin{tabular}{|c|c|c|c|c|}
\hline \multirow[t]{2}{*}{$\begin{array}{l}\text { Ingredientes } \\
\text { Ingredients }\end{array}$} & \multicolumn{4}{|c|}{$\begin{array}{c}\text { Tratamentos } \\
\text { Treatments }\end{array}$} \\
\hline & CAU & CFA & $\mathrm{CMM}$ & CFT \\
\hline $\begin{array}{l}\text { Cana-de-açúcar } \\
\text { Sugar cane }\end{array}$ & 95,16 & 84,16 & 83,12 & 83,44 \\
\hline $\begin{array}{l}\text { Uréia/AS } \\
\text { Urea/AS }\end{array}$ & 3,51 & 2,18 & 3,22 & 2,90 \\
\hline $\begin{array}{l}\text { Farelo de algodão } \\
\text { Cottonsed meal }\end{array}$ & - & 12,33 & - & - \\
\hline $\begin{array}{l}\text { Milho moído } \\
\text { Ground corn grain }\end{array}$ & - & - & 12,33 & - \\
\hline $\begin{array}{l}\text { Farelo de trigo } \\
\text { Wheat meal }\end{array}$ & - & - & - & 12,33 \\
\hline $\begin{array}{l}\text { Sal mineral } \\
\text { Mineral salt }\end{array}$ & 1,33 & 1,33 & 1,33 & 1,33 \\
\hline Total & 100 & 100 & 100 & 100 \\
\hline
\end{tabular}


A composição bromatológica dos ingredientes está apresentada na Tabela 2, e a das dietas, na Tabela 3. Todas as rações foram formuladas para apresentarem teores semelhantes de nutrientes digestíveis totais (NDT) e proteína bruta (PB). A mistura de uréia + sulfato de amônio foi preparada previamente, na proporção de 9:1, e fornecida juntamente com o concentrado, para os tratamentos CFA, CMM, CFT e, no tratamento CAU, foi diluída em água. A quantidade de água usada para diluição obedeceu a proporção de 4 litros para cada $100 \mathrm{~kg}$ de cana. Ao serem fornecidos no cocho, procedia-se o revolvimento dos alimentos, a fim de permitir melhor homogeneização dos ingredientes.

A alimentação foi à vontade, fornecida duas vezes ao dia, às $7(50 \%)$ e 15 horas $(50 \%)$, na forma de ração completa, com registros diários das quantidades fornecidas. Para garantir o consumo voluntário e manter os níveis dos diferentes ingredientes nos respectivos tratamentos foi realizado ajuste diário da quantidade de alimento oferecido, a fim de permitir sobras de 5 a $10 \%$ do total de matéria seca fornecida, também com registros diários.

Os alimentos fornecidos foram amostrados diariamente durante todos os períodos experimentais. Já as sobras foram coletadas nos períodos destinados à coleta, diariamente pela manhã, pesadas e armazenadas em freezer $\left(-20^{\circ} \mathrm{C}\right)$, sendo que no últi- mo dia de coleta, todas as amostras foram descongeladas e misturadas, perfazendo assim amostras compostas de cada tratamento, por período e por animal. Depois foram levadas à estufa de ventilação forçada à $65^{\circ} \mathrm{C}$ durante 48 horas, e acondicionadas em recipientes, devidamente identificados, para posterior moagem em moinho com peneira de malha de $1 \mathrm{~mm}$. As fezes foram coletadas diretamente do reto, no segundo e sexto dias de coleta, sendo no primeiro dia pela manhã e, no segundo, à tarde. Foi efetuado o mesmo procedimento relatado para as amostras de alimentos fornecidos e sobras.

As análises laboratoriais foram efetuadas no Laboratório de Nutrição Animal da UFRPE, segundo metodologia descrita por Silva (1990), para matéria seca (MS), matéria orgânica (MO), proteína bruta $(\mathrm{PB})$, extrato etéreo (EE), fibra em detergente neutro (FDN), fibra em detergente ácida (FDA) e matéria mineral (MM).

Os teores de carboidratos totais (CHT) e carboidratos não-fibrosos (CNF) foram calculados segundo equações descritas por Sniffen et al. (1992): $\mathrm{CHT}=100-(\mathrm{PB}+\mathrm{EE}+\mathrm{CINZAS})$ e Mertens (1997): $\mathrm{CNF}=100-(\mathrm{FDN}+\mathrm{PB}+\mathrm{EE}+\mathrm{CINZAS})$

$\mathrm{O}$ consumo de nutrientes digestíveis totais (CNDT), em quilogramas, e os teores de nutrientes digestíveis totais (NDT), em \%, foram calculados segundo Sniffen et al. (1992), pelas seguintes equa-

Tabela 2 - Composição bromatológica da cana-de-açúcar e dos concentrados Table 2 - Chemical composition of sugar cane and concentrates

\begin{tabular}{|c|c|c|c|c|}
\hline \multirow[t]{2}{*}{ Item } & \multicolumn{4}{|c|}{$\begin{array}{l}\text { Ingredientes } \\
\text { Ingredients }\end{array}$} \\
\hline & $\begin{array}{c}\text { Cana-de-açúcar } \\
\text { Sugar cane }\end{array}$ & $\begin{array}{c}\text { Farelo de algodão } \\
\text { Cottonseed meal }\end{array}$ & $\begin{array}{l}\text { Milho grão moído } \\
\text { Ground corn grain }\end{array}$ & $\begin{array}{c}\text { Farelo de trigo } \\
\text { Wheat meal }\end{array}$ \\
\hline$M S^{1}(D M)$ & 24,86 & 89,22 & 86,72 & 88,39 \\
\hline $\mathrm{MO}^{2}(O M)$ & 97,37 & 95,23 & 98,69 & 93,80 \\
\hline $\mathrm{PB}^{2}(C P)$ & 2,77 & 33,74 & 9,04 & 17,03 \\
\hline $\mathrm{EE}^{2}$ & 0,80 & 0,76 & 1,07 & 1,45 \\
\hline $\mathrm{FDN}^{2}(N D F)$ & 57,02 & 32,53 & 15,03 & 45,54 \\
\hline $\mathrm{FDA}^{2}(A D F)$ & 31,94 & 22,05 & 4,29 & 14,77 \\
\hline $\mathrm{CHT}^{2}(\mathrm{TCH})$ & 93,81 & 60,73 & 88,58 & 75,32 \\
\hline $\mathrm{CNF}^{2}(N F C)$ & 40,24 & 29,85 & 53,74 & 30,32 \\
\hline $\mathrm{MM}^{2}(A s h)$ & 2,63 & 4,77 & 1,31 & 6,20 \\
\hline $\mathrm{PIDN}^{2}(N D I C P)$ & 1,30 & 2,52 & 1,19 & 3,12 \\
\hline $\mathrm{PIDA}^{2}(A D I C P)$ & 0,74 & 1,86 & 0,50 & 1,18 \\
\hline $\mathrm{LIG}^{2}$ (Lignin) & 5,93 & 7,76 & 0,50 & 3,06 \\
\hline $\mathrm{LIG}^{4}$ (Lignin) & 10,40 & 23,86 & 1,38 & 6,71 \\
\hline $\mathrm{NDT}^{1,3}(T D N)$ & 62,05 & 63,78 & 83,68 & 65,66 \\
\hline
\end{tabular}

$1 \%$.

$2 \%$ da MS (\% in DM).

3 Estimado segundo o NRC (2001) (Estimated by NRC - 2001).

$4 \%$ da FDN (\% of NDF). 
Tabela 3 - Teores de matéria seca (MS), matéria orgânica (MO), proteína bruta (PB), extrato etéreo (EE), fibra em detergente neutro (FDN), fibra em detergente ácido (FDA), carboidratos totais (CHT), carboidratos não-fibrosos (CNF), matéria mineral (MM), lignina (LIG) e nutrientes digestíveis totais (NDT), conforme os tratamentos

Table 3 - Average contents of dry matter (DM), organic matter $(O M)$, crude protein $(C P)$, ether extract $(E E)$, neutral detergent fiber (NDF), acid detergent fiber (ADF), total carbohydrates (TCH), nonfibrous carbohydrate (NFC), ash, lignin (LIG) and total digestibible nutrients (TDN), according to the treatments

\begin{tabular}{|c|c|c|c|c|}
\hline \multirow[t]{2}{*}{ Item } & \multicolumn{4}{|c|}{$\begin{array}{c}\text { Tratamentos } \\
\text { Treatments }\end{array}$} \\
\hline & CAU & CFA & CMM & CFT \\
\hline $\mathrm{MS}^{1}(D M)$ & 28,45 & 35,40 & 35,86 & 35,83 \\
\hline $\mathrm{MO}^{2}(O M)$ & 92,66 & 93,69 & 94,12 & 93,51 \\
\hline $\mathrm{PB}^{2}(C P)$ & 12,46 & 12,59 & 12,43 & 12,53 \\
\hline $\mathrm{EE}^{2}$ & 0,76 & 0,77 & 0,75 & 0,85 \\
\hline $\mathrm{FDN}^{2}(N D F)$ & 54,26 & 52,00 & 49,25 & 53,20 \\
\hline $\mathrm{FDA}^{2}(A D F)$ & 30,39 & 29,60 & 27,07 & 28,47 \\
\hline $\mathrm{CHT}^{2}(\mathrm{TCH})$ & 89,27 & 86,43 & 88,89 & 87,56 \\
\hline $\mathrm{CNF}^{2}(N F C)$ & 38,29 & 37,55 & 42,62 & 37,31 \\
\hline $\mathrm{MM}^{2}($ Ash $)$ & 3,82 & 4,12 & 3,66 & 4,27 \\
\hline $\mathrm{LIG}^{2}$ (Lignin) & 5,65 & 5,95 & 4,99 & 5,33 \\
\hline $\mathrm{NDT}^{1,3}(T D N)$ & 59,05 & 60,09 & 61,90 & 59,87 \\
\hline
\end{tabular}

$1 \%$.

$2 \%$ da MS (\% in DM).

${ }^{3}$ Estimado segundo o NRC (2001) (Estimated by NRC - 2001).

$4 \%$ da FDN ( $\%$ of NDF).

ções: $\mathrm{CNDT}=(\mathrm{PB}$ ingerida $-\mathrm{PB}$ fecal $)+2,25(\mathrm{EE}$ ingerido-EEfecal $)+($ CHT ingerido - CHT fecal $)$ e NDT $(\%)=($ Consumo de NDT / Consumo de MS $) \times 100$.

$\mathrm{O}$ teor de gordura do leite foi determinado utilizando-se o método de Gerber, descrito por Behmer (1965). Para corrigir o leite para 4,0\% de gordura (LCG), utilizou-se a seguinte equação: LCG: 0,4 x (kg de leite) $+15 \times$ (kg de leite $\mathrm{x} \%$ de gordura) /100 (NRC, 1989).

Foi realizada apenas uma ordenha manual diária, às 5 horas, com exceção do segundo e sexto dias de coleta, onde foram realizadas duas ordenhas diárias, para coleta de amostras de leite, visando determinação do teor de gordura, sendo que a amostragem foi proporcional às produções da manhã e tarde. Nos outros dias foi permitido aos bezerros mamar o leite do período da tarde e a produção de leite foi estimada pela pesagem dos bezerros, antes e depois de mamar, em balança apropriada.

A variação do peso vivo das vacas foi avaliada por intermédio de pesagem no início e final de cada período. A pesagem foi realizada sempre no mesmo horário, após a ordenha da manhã, antes do fornecimento das dietas.

A estimativa da produção matéria seca fecal
(PMSF) foi obtida utilizando-se a fibra em detergente ácido indigestível (FDAi), como indicador interno (Berchielli et al., 2000). As amostras de fezes, sobras e alimentos foram acondicionadas em sacos de ANKOM e incubadas no rúmen de um bovino macho, adulto, por 144 horas. O material remanescente da incubação foi submetido à extração com detergente ácido, cujo resíduo foi considerado FDAi. Para o cálculo da PMSF foi utilizada a seguinte equação:

PMSF $(\mathrm{kg})=$ Consumo do indicador $(\mathrm{kg}) /$ Concentração do indicador nas fezes (\%)

O coeficiente de digestibilidade aparente (CD) dos nutrientes foi calculado como descrito por Coelho da Silva \& Leão (1979): CD = ((Cons. de nutrientes $(\mathrm{kg})$ - Nutrientes nas fezes $(\mathrm{kg})$ / Consumo de nutrientes $(\mathrm{kg})$ x 100 .

O delineamento experimental utilizado foi quadrado latino $4 \times 4$. Foram utilizados dois quadrados, de acordo com a ordem de lactação das vacas (primíparas e pluríparas).

Cada período experimental teve duração de 21 dias, sendo 14 dias de adaptação dos animais à nova dieta, e sete para coleta de dados e amostras, perfazendo quatro períodos experimentais, totalizando 84 dias. No início e final de cada período experimental, os animais foram pesados.

Os dados relativos à produção de leite sem e com correção para $4 \%$ de gordura; composição do leite; eficiência alimentar; consumo e digestibilidade dos nutrientes foram submetidos à análise de variância, e as médias, comparadas pelo teste de Tukey a 5\% de probabilidade, utilizando-se o programa SAEG 8.0 (Sistema de Análises Estatísticas e Genéticas) da Universidade Federal de Viçosa (UFV, 1998).

\section{Resultados e Discussão}

Na Tabela 4, são apresentados os resultados referentes aos consumos médios de matéria seca (MS), expressos em kg/dia, \% de peso vivo (PV) e em relação ao tamanho metabólico; fibra em detergente ácido (FDA), em kg/dia; fibra em detergente neutro (FDN), em kg/dia e \% de PV, bem como os respectivos coeficientes de variação $(\mathrm{CV})$, verificados para os diferentes tratamentos.

O baixo consumo de MS observado para todos os tratamentos pode ser explicado, provavelmente, pela baixa degradação da fibra no rúmen, o que limita o consumo pelo enchimento, em conseqüência do acúmulo de fibra não-digerível neste compartimento 
Tabela 4 - Consumos médios diários de matéria seca (CMS), fibra em detergente ácido (CFDA) e fibra em detergente neutro (CFDN), e coeficientes de variação $(\mathrm{CV})$, conforme os tratamentos

Table 4 - Average daily intakes ofdrymatter(DM), aciddetergent fiber (ADF), neutral detergent fiber (NDF), and coefficient of variation (CV), according to the treatments

\begin{tabular}{|c|c|c|c|c|c|}
\hline \multirow[t]{2}{*}{$\begin{array}{l}\text { Ingredientes } \\
\text { Ingredients }\end{array}$} & \multicolumn{4}{|c|}{$\begin{array}{c}\text { Tratamentos } \\
\text { Treatments }\end{array}$} & \multirow[t]{2}{*}{$\mathrm{CV}$} \\
\hline & $\mathrm{CAU}$ & CFA & CMM & CFT & \\
\hline $\begin{array}{l}\text { MS (kg) } \\
D M\end{array}$ & $5,32 \mathrm{~b}$ & $7,85 \mathrm{a}$ & $6,07 b$ & $7,60 \mathrm{a}$ & 14,30 \\
\hline MS (\% PV) & $1,30 \mathrm{~b}$ & $1,81 \mathrm{a}$ & $1,45 b$ & $1,78 \mathrm{a}$ & 12,65 \\
\hline $\begin{array}{l}D M(\% L W) \\
\mathrm{MS}(\mathrm{g} / \mathrm{kg} \mathrm{PV} 0,75) \\
D M\left(\mathrm{~g} / \mathrm{kg} \mathrm{LW} L W^{.75}\right)\end{array}$ & $58,38 \mathrm{~b}$ & $82,54 a$ & $65,41 \mathrm{~b}$ & $80,91 \mathrm{a}$ & 12,95 \\
\hline $\begin{array}{l}\text { FDA }(\mathrm{kg}) \\
A D F\end{array}$ & $1,62 b$ & $2,26 a$ & $1,55 \mathrm{~b}$ & $2,13 \mathrm{a}$ & 12,84 \\
\hline $\begin{array}{l}\text { FDN (kg) } \\
N D F\end{array}$ & $2,98 b$ & $3,96 a$ & $3,09 \mathrm{~b}$ & $4,01 \mathrm{a}$ & 13,91 \\
\hline $\begin{array}{l}\mathrm{FDN}(\% \mathrm{PV}) \\
N D F(\% L W)\end{array}$ & $0,73 b$ & $0,91 \mathrm{a}$ & $0,74 b$ & $0,94 a$ & 12,60 \\
\hline
\end{tabular}

Médias seguidas de letras diferentes, na mesma linha, diferem pelo teste Tukey $(\mathrm{P}<0,05)$.

Means followed by different letters, in a row, are different by Tukey test $(P<.05)$.

(Ærskov \& Hovell, 1978; Rodriguez, 1995; e Pereira et al., 2001). Pereira et al. (2000) verificaram elevado tempo de permanência $(28,56 \mathrm{~h})$ da fração fibrosa indigestível da cana-de-açúcar, o que poderia determinar menor ingestão de MS.

Observa-se que o consumo de MS, nas três formas em que foram expressos, foi superior $(\mathrm{P}<0,05)$ para os tratamentos CFA e CFT, em relação aos demais, o que está de acordo com Silvestre \& Hovell (1978), que, ao suplementarem cana-de-açúcar + uréia com farelo de trigo, verificaram aumento do consumo de MS, da taxa de substituição e do fluxo de líquidos com a suplementação. Neste sentido, Pereira et al. (2000) observaram que o farelo de algodão em suplementação à cana-de-açúcar proporcionou maior disponibilidade de energia ruminal, refletindo num melhor crescimento microbiano, resultando em maior consumo de MS. Estes mesmos autores verificaram que o farelo de algodão apresentou cerca de 72,48\% do seu conteúdo protéico, como frações de degradação intermediária e lenta, podendo ser utilizado para propiciar maior aporte de nitrogênio nos intestinos. Isso, é possível, pelo fato de o farelo de algodão e o farelo de trigo serem mais equilibrados quanto ao potencial de fornecimento de proteína e amido sobrepassantes, segundo classificação de Preston \&
Leng (1984), como podem ser verificados os maiores consumos de MS pelos animais alimentados com dietas contendo estes concentrados, que foram de 1,81 e $1,78 \%$ PV, respectivamente (Tabela 4).

Os dados diferem dos observados por Silvestre et al. (1977), quando suplementaram cana-de-açúcar + uréia com milho, e verificaram aumentos no consumo de MS.

Vale salientar também, que tanto as rações à base de cana-de-açúcar e uréia (CAU), quanto à base de milho (CMM) foram aquelas cujas quantidades de uréia foram as mais elevadas $(3,51$ e 3,22\% na MS, respectivamente), conforme pode ser observado na Tabela 1. Assim, a baixa palatabilidade da uréia pode ter contribuído para obtenção de menores ingestões de MS nestes tratamentos, conforme Huber \& Cook (1972), que atribuíram a redução no consumo em dietas com alto nível de uréia na ração à pouca palatabilidade desta.

Os resultados obtidos para o tratamento CAU foram inferiores aos observados por Pires et al. (1999), quando alimentaram vacas raça holandesas com 75 e $100 \%$ de cana-de-açúcar; bem como com os relatados por Ribeiro et al. (2000), de 1,57\% do PV, com $100 \%$ de cana na deita de vacas mestiças Holandês/Gir. Sucupira (1998) também observou redução no consumo de alimentos em vacas holandesas alimentadas com cana-de-açúcar, quando suplementadas com níveis crescentes de uréia $(1,0$; $1,5 ; 2,0 \%)$. Contudo, Moreira (1983), trabalhando com bovinos confinados, alimentados com cana mais uréia e diferentes concentrados, observou consumo de MS da ordem de 1,92 kg/100 kg PV para dietas contendo farelo de algodão.

Comportamento semelhante ao consumo de MS foi verificado para os consumos de FDA e FDN, expressos em kg/dia e \% PV apresentados na Tabela 4, que pode ser atribuído à diminuição no consumo de MS e as dietas apresentarem concentração semelhante destes nutrientes.

$\mathrm{Na}$ Tabela 5, são apresentados os resultados referentes aos consumos médios de matéria orgânica (CMO), proteína bruta (CPB), extrato etéreo (CEE), carboidratos totais (CCHT), carboidratos não-fibrosos (CCNF), e nutrientes digestíveis totais (CNDT) expressos em $\mathrm{kg} / \mathrm{dia}$; e CNDT, em $\mathrm{g} / \mathrm{kg}^{0,75}$, com respectivos coeficientes de variação, de acordo com os tratamentos.

O consumo de MO, PB, CHT, CNF e NDT, refletiu o comportamento verificado para o consumo de MS, mesmo havendo diferenças entre os tratamentos, ou seja, de forma geral os animais que 
receberam farelo de algodão e farelo de trigo consumiram mais estes nutrientes.

Na Tabela 6 são apresentados os coeficientes de digestibilidade aparente de matéria seca(CDMS), matéria orgânica (CDMO), proteína bruta (CDPB), extrato etéreo (CDEE), fibra em detergente neutro (CDFDN), fibra em detergente ácido (CDFDA) e carboidratos totais (CDCHT) e os teores de NDT, expressos em (\%), de acordo com os tratamentos experimentais, com seus respectivos coeficientes de variação.

Os coeficientes de digestibilidade da MS e MO, foram superiores $(\mathrm{P}<0,05)$ para o tratamento $\mathrm{CMM}$, o que já era esperado, em virtude de os teores de CNF e FDN neste tratamento, terem sido, maiores e menores, respectivamente, em relação aos demais, como pode ser visualizado na Tabela 3. Já o tratamento CFA apresentou o menor digestibilidade $(\mathrm{P}<0,05)$ para $\mathrm{PB}$, comportamento que pode ser explicado pelo fato de o farelo de algodão possuir maior potencial

Tabela 5 - Consumos médios diários de matéria orgânica $(\mathrm{CMO})$, proteína bruta (CPB), extrato etéreo (CEE), carboidratos totais (CCHT), carboidratos não-fibrosos (CCNF) e nutrientes digestíveis totais (CNDT), e coeficientes de variação (CV), conforme os tratamentos

Table 5 - Average daily intakes of organic matter (OM), crude protein (CP), ether extract (EE), total carbohydrates (THC), nonfiber carbohydrates (NFC), total digestible nutrients (TDN), coefficient of variation $(\mathrm{CV})$, according to the treatments

\begin{tabular}{|c|c|c|c|c|c|}
\hline \multirow[t]{2}{*}{$\begin{array}{l}\text { Item } \\
\text { Item }\end{array}$} & \multicolumn{4}{|c|}{$\begin{array}{c}\text { Tratamentos } \\
\text { Treatments }\end{array}$} & \multirow[t]{2}{*}{$\mathrm{CV}$} \\
\hline & CAU & CFA & CMM & CFT & \\
\hline $\begin{array}{l}\text { MO (kg/dia) } \\
D M(k g / d a y)\end{array}$ & $5,21 b$ & $7,62 \mathrm{a}$ & $5,94 b$ & $7,38 \mathrm{a}$ & 14,23 \\
\hline $\begin{array}{l}\text { PB (kg/dia) } \\
C P \text { (kg/day) }\end{array}$ & $0,82 \mathrm{c}$ & $1,20 \mathrm{a}$ & $0,93 \mathrm{bc}$ & $1,14 \mathrm{ab}$ & 15,22 \\
\hline $\begin{array}{l}\mathrm{PB}\left(\mathrm{g} / \mathrm{kg}^{0,75}\right) \\
C P\left(\mathrm{~g} / \mathrm{kg} \mathrm{LW}^{75}\right)\end{array}$ & $8,93 \mathrm{c}$ & $12,65 a$ & $10,03 b c$ & $12,14 \mathrm{ab}$ & 14,12 \\
\hline $\begin{array}{l}\mathrm{EE} \text { (kg/dia) } \\
E E \text { (kg/day) }\end{array}$ & $0,049 \mathrm{c}$ & $0,068 \mathrm{ab}$ & $0,057 \mathrm{bc}$ & $0,071 \mathrm{a}$ & 14,08 \\
\hline $\begin{array}{l}\text { CHT (kg/dia) } \\
T C H \quad(k g / d a y)\end{array}$ & $5,14 b$ & $7,05 \mathrm{a}$ & $5,77 \mathrm{ab}$ & $7,05 \mathrm{a}$ & 13,83 \\
\hline $\begin{array}{l}\text { CNF (kg/dia) } \\
N F C \quad(k g / d a y)\end{array}$ & $2,40 \mathrm{~b}$ & $3,37 \mathrm{a}$ & $2,93 \mathrm{ab}$ & $3,61 \mathrm{a}$ & 14,03 \\
\hline $\begin{array}{l}\text { NDT (kg/dia) } \\
D M(k g / d a y)\end{array}$ & $4,30 \mathrm{~b}$ & $5,64 a$ & $5,12 \mathrm{ab}$ & $5,87 \mathrm{a}$ & 14,50 \\
\hline $\begin{array}{l}\text { NDT }\left(\mathrm{g} / \mathrm{kg}^{0,75}\right) \\
\operatorname{TDN}\left(\mathrm{g} / \mathrm{kg} \mathrm{LW} W^{75}\right)\end{array}$ & $47,18 b$ & $59,31 \mathrm{a}$ & $55,19 \mathrm{ab}$ & $62,54 a$ & 13,16 \\
\hline
\end{tabular}

Médias seguidas de letras diferentes, na mesma linha, diferem entre si pelo teste Tukey $(\mathrm{P}<0,05)$.

Means followed by different letters, in a row, are different by Tukey test $(P<.05)$.

R. Bras. Zootec., v.32, n.3, p.768-777, 2003 para proteína sobrepassante (Preston \& Leng, 1984 e Pereira et al., 2000). Os dados obtidos para os coeficientes de digestibilidade da MS de 64,83; 63,03; 70,46 e $65,39 \%$ para os tratamentos CAU, CFA, CMM e CFT, respectivamente, estão de acordo com os valores encontrados na literatura consultada com dietas à base de cana, que variaram de 53,85 a 71,61\% (Ferreiro \& Preston, 1977; Rodriguez \& Corvea, 1983; Aroeira et al., 1993; Ferreiro et al., 1997; Pereira et al., 2001).

O coeficiente de digestibilidade da FDA variou de 35,03 a 46,3\% entre os tratamentos, sendo que os tratamentos CMM, CAU e CFT foram superiores $(\mathrm{P}<0,05)$ em relação à dieta contendo farelo de

Tabela 6 - Coeficientes de digestibilidade aparente de matéria seca (CDMS), matéria orgânica (CDMO), proteína bruta (CDPB), extrato etéreo (CDEE), fibra em detergente neutro (CDFDN), fibra em detergente ácido (CDFDA), carboidratos totais (CDCHT), carboidratos não-fibrosos (CDCNF), e teores de nutrientes digestíveis totais (NDT) e coeficientes de variação (CV), conforme os tratamentos

Table 6 - Apparent digestibility coefficients of dry matter (DCDM), organic matter (DCOM), crude protein $(D C C P)$, ether extract (DCEE), neutral detergent fiber (DCNDF), acid detergent fiber (DCADF), total carbohydrates (DCTCH), nonfiber carbohydrates (DCNFC), total digestibible nutrients (TDN) and coefficients of variation $(C V)$, according to the treatments

\begin{tabular}{|c|c|c|c|c|c|}
\hline \multirow[t]{2}{*}{$\begin{array}{l}\text { Item } \\
\text { Item }\end{array}$} & \multicolumn{4}{|c|}{$\begin{array}{c}\text { Tratamentos } \\
\text { Treatments }\end{array}$} & \multirow[t]{2}{*}{$\mathrm{CV}$} \\
\hline & $\mathrm{CAU}$ & CFA & CMM & CFT & \\
\hline $\begin{array}{l}\text { CDMS } \\
D C D M\end{array}$ & $64,83 b$ & $63,03 b$ & $70,46 a$ & $65,39 b$ & 2,93 \\
\hline $\begin{array}{l}\text { CDMO } \\
D C O M\end{array}$ & $66,73 b$ & $64,76 b$ & $71,85 \mathrm{a}$ & $67,01 b$ & 2,78 \\
\hline $\begin{array}{l}\text { CDPB } \\
D C C P\end{array}$ & $79,00 \mathrm{a}$ & $73,89 b$ & $80,85 a$ & $78,31 \mathrm{a}$ & 3,68 \\
\hline $\begin{array}{l}\text { CDEE } \\
D C E E\end{array}$ & $45,77 \mathrm{a}$ & $42,57 \mathrm{a}$ & $55,01 \mathrm{a}$ & $47,06 a$ & 19,86 \\
\hline $\begin{array}{l}\text { CDFDN } \\
D C N D F\end{array}$ & $49,74 \mathrm{ab}$ & $40,21 \mathrm{c}$ & $53,66 a$ & $46,21 b$ & 5,78 \\
\hline $\begin{array}{l}\text { CDFDA } \\
D C A D F\end{array}$ & $43,12 \mathrm{a}$ & $35,03 b$ & $46,30 \mathrm{a}$ & $42,21 \mathrm{a}$ & 11,14 \\
\hline $\begin{array}{l}\text { CDCHT } \\
D C T C H\end{array}$ & $70,14 b$ & $66,79 c$ & $74,59 a$ & $69,56 b$ & 2,48 \\
\hline $\begin{array}{l}\text { CDCNF } \\
D C N F C\end{array}$ & $98,31 \mathrm{a}$ & $99,99 a$ & $98,73 a$ & $99,99 a$ & 2,77 \\
\hline $\begin{array}{l}\text { NDT } \\
T D N\end{array}$ & $85,20 \mathrm{a}$ & $74,44 \mathrm{c}$ & $88,25 \mathrm{a}$ & $80,88 b$ & 2,70 \\
\hline
\end{tabular}

Médias seguidas de letras diferentes, na mesma linha, diferem entre si pelo teste Tukey $(\mathrm{P}<0,05)$.

Means followed by different letters, in a row, are different by Tukey test $(P<.05)$. 
algodão (CFA), provavelmente, pelo maior teor de lignina nesta dieta Tabela 3.

Os coeficientes de digestibilidade da FDN e CHT tenderam a serem superiores para os tratamentos com maior proporção de uréia, CAU e CMM. Este comportamento está de acordo com Aroeira et al. (1993), que observaram aumento da digestibilidade da FDN, com o acréscimo nos níveis de uréia $(1,0$; 1,$5 ;$ e $2,0 \%$ da cana fresca). O mesmo foi observado por Rodriguez \& Corvea (1983), com semelhantes níveis de uréia para cana. Então, o menor consumo nas dietas CAU e CMM, provavelmente, provocado pelo maior tempo de retenção no rúmen, o que segundo Stacchini (1998), aumentaria a digestão dos nutrientes neste compartimento.

Para o coeficiente de digestibilidade dos CNF não houve diferença $(\mathrm{P}>0,05)$ entre os tratamentos. Isso, provavelmente, foi devido à grande quantidade de cana-de-açúcar nas dietas Tabela 2, que apresenta elevada quantidade de carboidratos solúveis.

Os teores de NDT foram superiores $(\mathrm{P}<0,05)$ para os tratamentos $\mathrm{CMM}$ e $\mathrm{CAU}$, em relação aos CFT e CFA, e o CFT foi maior $(\mathrm{P}<0,05)$ que CFA.

$\mathrm{Na}$ Tabela 7 são apresentados os resultados médios referentes à produção de leite e produção de leite corrigida a 4,0\% de gordura, expressas em kg/ dia; teores de proteína e gordura do leite, expressos em \%; e produções de proteína e gordura, expressas em g/dia; eficiência alimentar ( $\mathrm{kg}$ leite/kg de matéria seca ingerida) e os respectivos coeficientes de variação $(\mathrm{CV})$, conforme os tratamentos.

A produção de leite observada foi maior $(\mathrm{P}<0,05)$ para o tratamento CFT, em relação ao CAU. Entretanto, para os demais tratamentos não houve $(\mathrm{P}>0,05)$ diferenças. Contudo, quando a produção de leite corrigida o tratamento CAU foi inferior $(\mathrm{P}<0,05)$, em relação aos demais.

Nogueira Filho et al. (1977) observaram diminuição na produção de leite, quando a cana-de-açúcar substituiu acima de $50 \%$ a silagem de milho, para grupo de vacas mestiças. Estes mesmos autores também observaram perda de peso da ordem de $1 \mathrm{~kg} / \mathrm{dia}$, quando a cana substituiu $100 \%$ da dieta de silagem de milho.

O mesmo comportamento foi demonstrado por Paiva et al. (1991), quando compararam a cana e uréia como dieta exclusiva, suplementada com $4 \mathrm{~kg}$ de concentrado à silagem de milho. Os autores concluíram que cana e uréia, como dieta exclusiva, não proporcionaram desempenho satisfatório para produção de leite de vacas mestiças. Estes autores também
Tabela 7 - Produções de leite observada (PL) e corrigida para $4 \%$ de gordura (PLCG), teores e quantidades de proteína bruta (PB) e gordura (G), e eficiência alimentar $\mathrm{kg}$ de leite/kg de MS (EA) e coeficientes de variação (CV), conforme os tratamentos

Table 7 - Milk production observed (MP) and corrected for $4 \%$ fat (MPCF), contents and amounts of crude protein $(C P)$ and fat $(F)$, feed efficiency $\mathrm{kg}$ milk/kg $D M$ (FE) and coefficients of variation (CV), according to the treatments

\begin{tabular}{|c|c|c|c|c|c|}
\hline \multirow[t]{2}{*}{$\begin{array}{l}\text { tem } \\
\text { Item }\end{array}$} & \multicolumn{4}{|c|}{$\begin{array}{c}\text { Tratamentos } \\
\text { Treatments } \\
\end{array}$} & \multirow[t]{2}{*}{$\mathrm{CV}$} \\
\hline & CAU & CFA & CMM & CFT & \\
\hline $\begin{array}{l}\text { PL ( } \mathrm{kg} / \text { dia }) \\
M P(k g / \text { day })\end{array}$ & $6,45 b$ & $7,35 \mathrm{ab}$ & $7,13 \mathrm{ab}$ & $7,71 \mathrm{a}$ & 8,89 \\
\hline $\begin{array}{l}\text { PLCG (kg/dia) } \\
M P C F \text { (kg/day) }\end{array}$ & $5,85 b$ & $6,68 \mathrm{a}$ & $6,55 a$ & $7,11 \mathrm{a}$ & 6,68 \\
\hline $\begin{array}{l}\mathrm{PB}(\%) \\
C P(\%)\end{array}$ & $2,59 \mathrm{a}$ & $2,85 a$ & $2,94 a$ & $2,82 \mathrm{a}$ & 9,96 \\
\hline $\begin{array}{l}\mathrm{PB} \quad(\mathrm{g} / \mathrm{dia}) \\
C P(\mathrm{~kg} / \mathrm{day})\end{array}$ & $164,86 b$ & $211,27 \mathrm{a}$ & $207,70 \mathrm{a}$ & $214,45 \mathrm{a}$ & 13,54 \\
\hline $\begin{array}{l}\mathrm{G}(\%) \\
F(\%)\end{array}$ & $3,33 \mathrm{a}$ & $3,48 \mathrm{a}$ & $3,66 a$ & $3,55 a$ & 7,68 \\
\hline $\begin{array}{l}\mathrm{G}(\mathrm{g} / \mathrm{dia}) \\
F(\mathrm{~kg} / \text { day })\end{array}$ & $217,76 b$ & $249,06 a$ & $246,06 a b$ & $268,05 \mathrm{a}$ & 7,85 \\
\hline $\begin{array}{l}\text { EA } \\
F E\end{array}$ & $1,10 \mathrm{a}$ & $0,87 b$ & $1,14 \mathrm{a}$ & $0,97 \mathrm{ab}$ & 14,96 \\
\hline
\end{tabular}

Médias seguidas de letras diferentes, na mesma linha, diferem entre si pelo teste Tukey $(\mathrm{P}<0,05)$.

Means followed by different letters, in a row, are different by Tukey test $(P<.05)$.

encontram perdas de peso da ordem de $0,60 \mathrm{~kg} / \mathrm{dia}$. Como também Naufel et al. (1969), ao avaliarem, a cana-de-açúcar como único volumoso para vacas em lactação, observaram redução na produção de leite, e drástica perda de peso, de aproximadamente, $1 \mathrm{~kg} /$ dia. Isso foi verificado neste estudo onde a perda de peso foi de 0,8; 0,2 e 0,6 e ganho de 0,1 kg/dia, respectivamente, para os tratamentos CAU, CFA, CMM e CFT. No entanto, Biondi et al. (1978) não observaram diferenças nas produções de leite de vacas mestiças, quando da substituição da silagem de milho por cana-de-açúcar $(0 ; 25 ; 50 ; 75$ e $100 \%)$, que obtiveram na substituição total a produção de $8,8 \mathrm{~kg} /$ dia de leite, entretanto esta dieta teve a suplementação de $1 \mathrm{~kg}$ de concentrado para cada 2,5 kg /leite.

Os resultados observados estão de acordo com Preston \& Leng (1980) e Boin \& Tedeschi (1993), onde observaram que a cana-de-açúcar suplementada apenas com minerais e uréia, proporcionou nutrientes adequados para mantença e para baixos desempenhos produtivos em bovinos. Por outro lado, Fernandes et al. (2001), em simulação de dieta a base de cana- 
de-açúcar e uréia pelo sistema Cornell (CNCPS) para vacas mestiças de baixo potencial, estimaram a produção de leite em 7,5 kg/dia.

Para os teores de proteína e gordura do leite, expressos em \%, não foram observadas diferença (P> 0,05) entre os tratamentos, cujos valores médios foram de 2,8 e $3,5 \%$, respectivamente, para proteína e gordura. Já as produções de proteína e gordura do leite, acompanharam as produções de leite corrigidas.

A eficiência alimentar foi superior $(\mathrm{P}<0,05)$ para os tratamentos CAU e CMM em relação ao contendo farelo de algodão (CFA). Isso em detrimento das maiores perdas de peso nestes dois tratamentos, como foi relatado anteriormente.

\section{Conclusões}

Para vacas mestiças de baixo potencial de produção a suplementação que apresentou os melhores resultados, baseados na produção e composição do leite, consumo de matéria seca, digestibilidade dos nutrientes e eficiência alimentar, foi com farelo de trigo.

\section{Literatura Citada}

ALLEN, M.S. Relationship between forage quality and dairy cattle production. Animal Feed Science and Technology, v.59, p.51-60, 1996.

ALVAREZ FLORES, F.J. Utilización de la caña de azúcar como forrage para la producción de leche y carne bovina em el tropico. In: TÉCNICAS MODERNAS DE PRODUCCIÓN ANIMAL EN EL TROPICO, 1980, Honduras.Simpósio... Honduras: Ministério de Recursos Naturales, 1980. p.19-34.

ARMENTANO, L.; PEREIRA, M. Measuring the effectiveness fiber by animal response trials. Journal of Dairy Science, v.80, n.7, p.1416-1425, 1997.

AROEIRA, L.J.M.; LOPES, F.C.F.; DEREA, F.V. et al. Degradabilidade "in situ" dos nutrientes da cana-de-açúcar e do farelo de algodão em novilhos alimentados com farelo de algodão e cana-de-açúcar adicionada de três níveis de uréia. Arquivo Brasileiro de Medicina Veterinária e Zootecnia, v.45, n.4, p.221-233, 1993a.

ASSIS, A.G. Alimentação de vacas leiteiras. Coronel Pacheco: Embrapa Gado de Leite, 1986. 54p. (Documentos, 26).

BEHMER, M.L.A. Laticínios, leite, manteiga, queijo, caseína e instalações. 3.ed. São Paulo: Melhoramento, 1965. 294p.

BERCHIELLI, T.T.; ANDRADE, P.; FURLAN, C.L. Avaliação de indicadores internos em ensaios de digestibilidade.Revista Brasileira de Zootecnia, v.29, n.3, p.830-833, 2000.

BIONDI, P.; CAIELLI, E.L.; FREITAS, E.A.N. et al. Substituição parcial e total da silagem de milho por cana-de-açúcar como únicos volumosos para vacas em lactação. Boletim Indústria Animal, v.35, n.1, p.45-55, 1978.

BOIN, C.; TEDESCHI, L.O. Cana-de-açúcar na alimentação de gado de corte In: SIMPÓSIO SOBRE NUTRIÇÃO DE
BOVINOS, 5., 1993, Piracicaba. In: Anais... Piracicaba: Fundação de Estudos Agrários Luiz de Queiroz, 1993. p.107-126.

CAIELLI, R.L. Engorda de novilhos com cana-de-açúcar, capimelefante Napier e concentrados. Boletim de Indústria Animal, v.32, n.1, p.29-36, 1975.

COELHO DA SILVA, J.F.C.; LEÃO, M. I. Fundamentos de nutrição de ruminantes. Piracicaba: Livroceres. 1979. 380p.

FERNANDES, A.M.; QUEIROZ, A.C.; LANA, R.P. et al. Estimativas da produção de leite por vacas holandesas mestiças, segundo o sistema CNCPS, em dietas contendo cana-de-açúcar com diferentes valores nutritivos. Revista Brasileira de Zootecnia, v.30, n.4, p.1350-1357, 2001.

FERREIRO, H.M.; ELLIOTT, R.; PRESTON, T.R. The effect of energy rich feed supplements on the availability of nutrients in the duodenum of cattle fed sugar cane. Tropical Animal Production, v.4, n.3, p.248-254, 1979.

FERREIRO, H.M.; PRESTON, T.R. Digestibility and voluntary intake of derinded sugar cane stalk with and without addition of cane tops. Tropical Animal Production, v.2, n.1, p.90-99, 1977.

FERREIRO, H.M.; PRESTON, T.R.; SUTHERLAND, T.M. Investigation of dietary limitations on sugar cane based diets. Tropical Animal Production, v.2, n.1, p.56-61, 1997.

HEAD, H. H. Manejo de animais em sistema de estabulação livre visando maximizar conforto e produção. In: MOURA, J.C.; FARIA, V.P.; MATTOS, W.R.S. (Ed). Conceitos modernos de exploração leiteira. Piracicaba: Fundação de Estudos Agrários Luiz de Queiroz, 1995. p.41-68.

HOOVER, W.H. Chemical factors involved in ruminal fiber digestion. Journal of Dairy Science, v.69, n.10, p.27552766, 1986.

HOOVER, W.H; STOKES, S.R. Balancing carbohydrates and proteins for optimum rumen microbial yield. Journal of Dairy Science, v.74, n.10, p.3630-3644, 1991.

HUBER, J.T.; COOK, R.M. Influence of site of administration of urea on voluntary intake of concentrate by lactating cows. Journal of Dairy Science, v.64, n.6, p.1170-1195, 1972.

KENNELLY, J.J.; GLIMM, D.R.; OZIMEK, L.Milk composition in the cow. 1999. Disponível em: <www.ansci.cornell.edu/dm/ dm.html>. Acesso em: 27 jan. 2002.

LENG, R.A. Limitações metabólicas en la utilización de al cana de azúcar y sus derivados para el crecimiento e producción de leche en rumiantes. In: SISTEMAS INTENSIVOS PARA PRODUCCIÓN ANIMAL Y ENERGÍA RENOVABLE COL RECURSOS TROPICALES, 1988, Cali. Simpósio... Cali: CPAC, 1988. p.31-38.

LIMA, M.L.M., MATTOS, W.R.S. Cana-de-açúcar na alimentação de bovinos leiteiros. In: SIMPÓSIO SOBRE NUTRIÇÃO DE BOVINOS, 5., 1993, Piracicaba. Anais... Piracicaba: Fundação de Estudos Agrários Luiz de Queiroz, 1993. p.77-105.

McDONALD, P.; EDWARDS, R.; GREENHALGH, J.F.D. Nutrition animal.4.ed. Zaragoza: Acríbia. 1993. 571p.

MERTENS, D.R. Creating a system for meeting the fiber requirements of dairy cows. Journal of Dairy Science, v.80, n.8, p.1463-1469, 1997.

MOREIRA, H.A. Cana-de-açúcar na alimentação de bovinos. Informe Agropecuário, v.9, n.108, p.14-16, 1983.

NATIONAL RESEARCH COUNCIL - NRC. Nitrogen usage in ruminants. Washington, D.C.: National Academy Press, 1985. $148 \mathrm{p}$.

NATIONAL RESEARCH COUNCIL - NRC. Nutrients requirements of dairy cattle. 7.ed. Washington, D.C.: National Academy Press, 2001. 408p. 
NATIONAL RESEARCH COUNCIL - NRC. Nutrients requirements of dairy cattle. 6.ed. Washington, D.C.: National Academy Press, 1989. 112p.

NAUFFEL, F.; GOLDM AN, E.F.; GUARAGNA, R.N. et al. Estudo comparativo entre a cana-de-açúcar e silagens de milho, sorgo e capim-napier na alimentação de vacas leiteiras. Boletim Indústria Animal, v.26 (único), p.9-22, 1969.

NOGUEIRA FILHO, J.C.M.; LUCCI, C.S.; ROCHA, G.L. et al. Substituição parcial da silagem de sorgo por cana-de-açúcar como únicos volumosos para vacas em lactação. Boletim Indústria Animal, v.34, n.1, p.75-84, 1977.

OBA, M.; ALLEN, M.S. Evaluation of the importance of the digestibility of neutral detergent fiber from forage: effects on dry matter intake and milk yield of dairy cows. Journal of Dairy Science, v.82, n.3, p.589-596, 1999.

ORSKOV, W.R.; HOVELL, F.D.D. Digestión ruminal del heno (medido através de bolsas de dacron) en el ganado alimentado con caña de azúcar e heno de pangola. Tropical Animal Production, v.3, n.1, p.9-11, 1978.

PAIVA, J.A.J.; MOREIRA, H.A.; CRUZ, G.M. et al.. Cana-deaçúcar associada a uréia/sulfato de amônio como volumoso exclusivo para vacas em lactação. Revista Brasileira de Zootecnia, v.20, n.1, p.90-99, 1991.

PEREIRA, E.S.; QUEIROZ, A.C.; PAULINO, M.F. et al. Determinação das frações protéicas e de carboidratos e taxas de degradação in vitro da cana-de-açúcar, da cama de frango e do farelo de algodão. Revista Brasileira de Zootecnia, v.29, n.6, p.1887-1893, 2000.

PEREIRA, E.S.; QUEIROZ, A.C.; PAULINO, M.F. et al. Fontes nitrogenadas e uso de Sacharomyces cerevisiae em dietas à base de cana-de-açúcar para novilhos: consumo, digestibilidade, balanço nitrogenado e parâmetros ruminais. Revista Brasileira de Zootecnia, v.30, n.2, p.563-572, 2001.

PIRES, A.V.; SIMAS, J.M.C.; ROCHA, M.H.M. et al. Efeito da substituição da silagem de milho pela cana-de-açúcar no consumo de matéria seca, parâmetros ruminais, produção e composição do leite de vacas holandesas. In: REUNIÃO ANUAL DA SOCIEDADE BRASILEIRA DE ZOOTECNIA, 36., 1999, Porto Alegre. Anais... Porto Alegre. SBZ/Gnosis, [1999]. CD-ROOM. Nutrição de Ruminantes - Fermentação ruminal. NUR - 057.

PIRES, M.F.A.; VILELA, D.; VERNEQUE, R.S. et al. Reflexos do estresse térmico no comportamento das vacas em lactação. In: IRAN, J. O. S. Ambiência na produção de leite. 1ed. Piracicaba: Fundação de Estudos Agrários Luiz de Queiroz, 1998, p.68-102.

PRESTON, T.R.; LENG, R.A. Matching ruminant production systems with available resources in the tropics and subtropics. In: MACLEOD, N.A.; SUTHERLAND, T.M. Penambul Books. Zaragoza: Acríbia, 1986. 100p.

PRESTON, T.R.; LENG, R.A. Supplementation of diets based on fibrous residues and by-products. In: SUNDSTOL, F; OWEN, E. Straw and other fibrous by-products as feed: developments in animal and veterinary sciences. Amsterdam: Elsevier, 1984. p.373-413.

PRESTON, T.R. Nutricional limitations associated with the feeding of tropical forages. Journal of Animal Science, v.54, n.4, p.877-883, 1982.

PRESTON, T.R. The use of sugar cane and by-products for livestock. In: REUNIÃO ANUAL DA SOCIEDADE BRASILEIRA DE ZOOTECNIA, 21., 1984, Belo Horizonte. Anais... Belo Horizonte: Sociedade Brasileira de Zootecnia, 1984. p.14-19.
PRESTON, T.R.; LENG, R.A. Utilization of tropical feeds by ruminants. In: Digestive physiology and metabolism in ruminants. Westport: AVI, 1980. p. 620-640.

PRIEGO, A.; LORA, J.A. Efecto da la frecuencia alimenticia y la suplementacion con afrecho de trigo sobre el consumo voluntario y función ruminal en ganado bovino alimentado con caña de azúcar. Tropical Animal Production, v.3, n.1, p.211-217, 1978.

RAVELO, G.; GONZALEZ, F.; DEBHOVELL, F. D. El efecto de alimentar por fístula ruminal caña de azúcar e afrecho de trigo sobre el consumo de caña de azúcar. Tropical Animal Production, v. 3, n.3, p.237-242, 1978.

RIBEIRO, E. G.; ESTRADA, L. H.C.; FONTES, C. A. A. et al. Níveis de substituição da silagem de milho pela cana-deaçúcar na alimentação de vacas de leite (consumo alimentar). In: REUNIÃO ANUAL DA SOCIEDADE BRASILEIRA DE ZOOTECNIA, 37., 2000, Viçosa, MG. Anais... Viçosa: SBZ/Gnosis, [2000]. CD-ROOM. NUR - 0579.

RODRIGUEZ, V.; CORVEA, E. R. Utilización de la caña de azúcar entera como fuente de forraje en la alimentación del ganado. In: OWEN, E.Producción y uso de alimentos para la nutrición animal a partir de la caña de azúcar.Havana: Centro de información y divulgación agropecuario. 1983. $11 \mathrm{p}$.

SILVA, D.J. Análise de alimentos (métodos químicos e biológicos). 2.ed. Viçosa, MG: Universidade Federal de Viçosa, 1990. 165p.

SILVESTRE, R.; MACLEOD, N.A.; PRESTON, T.R. Supplementation of sugar cane/urea for growing cattle: effect of maize grain and differente levels and sources of protein. Tropical Animal Production, v.2, n.1, p.81-89, 1977.

SILVESTRE R.; HOVELL, F.D. Growth of fattening cattle given chopped sugar cane supplemented with different levels of wheat bran. Tropical Animal Production, v.3, n.2, p.148$151,1978$.

SNIFFEN, C.J.; O' CONNOR, J.D.; Van SOEST, P. J. et al. A net carbohydrate and protein system for evaluating cattle diets. II. Carbohydrate and protein availability. Journal of Animal Science, v.70, n.7, p.3562-3577, 1992.

STACCHINI, P.F. Efeito dos teores de uréia e do farelo de soja a digestibilidade e balanço de $\mathbf{N}$ em vacas leiteiras alimentadas com cana-de-açúcar. Piracicaba: Escola Superior de Agricultura "Luiz de Queiroz", 1998. 67p. Dissertação (Mestrado em Ciência Animal e Pastagens) Escola Superior de Agricultura "Luiz de Queiroz”, 1998.

SUCUPIRA, M.C.A. Efeito dos níveis crescentes de uréia no consumo, volume e taxa de passagem em vacas holandesas alimentadas com cana-de-açúcar. Piracicaba: Escola Superior de Agricultura "Luiz de Queiroz", 1998. 66p. Dissertação (Mestrado em Ciência Animal e Pastagens) Escola Superior de Agricultura "Luiz de Queiroz", 1998.

UNIVERSIDADE FEDERAL DE VIÇOSA.Sistema de análise estatística e genética. versão 8.0. Viçosa, MG: Universidade Federal de Viçosa, 1998.

Van SOEST, P.J. Nutritional ecology of the ruminant. 2.ed. New York: Cornell University Press. 1994. 476p.

WARNAARS, B.C. Growing of sugar cane as an animal feed. World Animal Review, v.11, n.3, p.1-5, 1974. 